\title{
La consagración de los derechos fundamentales: de principios generales a texto fundacional de la Unión Europea*
}

\author{
Luis Jimena Quesada \\ Catedrático de Derecho Constitucional \\ Universidad de Valencia
}

\begin{abstract}
Sumario: I. Introducción: rememorando la evolución de la consagración jurídica de los derechos fundamentales como salto cualitativo de apariencia constitucional en la Unión Europea (UE). - II. La Carta de los Derechos Fundamentales (CDFUE) ante el dilema estatuto formal-real efectividad. 1. Un catálogo, al menos, triplemente asimétrico. 2. La posición del Tribunal de Justicia de la Unión Europea (TJUE) ante la CDFUE: la diferencia cualitativa de su labor pretoriana con o sin base normativa. - III. Retos pendientes, pese a la CDFUE: armonización interpretativa, armonización normativa y crisis económica. 1. La voluntad jurisdiccional positiva del TJUE al acometer los contenciosos paralelos a escala internacional. 2. El diálogo judicial del TJUE con las jurisdicciones nacionales. 3. El TJUE: ¿promotor de la primacía y desalentador del control de convencionalidad? 4. La insuficiencia de la adhesión de la UE al Convenio Europeo de Derechos Humanos (CEDH). 5. La consideración de la CDFUE como verdadero texto fundacional ante las medidas anti-crisis. - IV. Conclusión: superando pequeños pasos y tropiezos en el camino de la consagración jurídica de los derechos fundamentales.
\end{abstract}

Resumen: El autor argumenta que el reconocimiento formal de los derechos fundamentales como parte de los fundamentos comunes de la UE mediante la remisión a la Carta de los Derechos Fundamentales en el Tratado de Lisboa (otorgándole carácter vinculante $\mathrm{y}$, por ende, elevando su rango y confiriéndole el mismo valor jurídico que los Tratados) ha proporcionado una mayor apariencia constitucional a la UE, pero no un nivel más generoso de protección y de disfrute de la ciudadanía. En efecto, además de haber prescindido de garantías específicas, la Carta de la UE ha introducido diversas asimetrías inaceptables, tales como la quiebra del principio de indivisibilidad (los derechos civiles y los sociales no son tratados en pie de igualdad) o la presunta exclusión de diferentes países (República Checa, Polonia y Reino Unido) con respecto a la aplicabilidad de la Carta de

* Recibido 2 de diciembre de 2013, aceptado el 7 de enero de 2014. 
la UE. En este contexto, sobre sostener que la formulación de los derechos fundamentales en la Carta de la UE no puede implicar una concepción más estrecha que la desarrollada por el Tribunal de Justicia en su jurisprudencia sobre derechos humanos (como parte de los principios generales del Derecho Comunitario), el ensayo contiene argumentos para superar dichas asimetrías poniendo el acento en la necesidad de voluntad positiva con objeto de reforzar el diálogo judicial sobre la base de las cláusulas de la Carta de la UE que promueven la protección multinivel y el principio favor libertatis. En fin, el autor sugiere que si se explotan tales sinergias y toman en consideración otros instrumentos europeos de derechos humanos, se robustecerá la posición de la Carta de los Derechos Fundamentales incluso en el marco de la UE (por ejemplo frente a las medidas de austeridad lanzadas por la Troika) y, por tanto, ello mejorará la eficiencia y la legitimidad democrática de la Unión, así como la coherencia de su acción.

Palabras clave: Derechos fundamentales indivisibles, diálogo judicial y sinergias, armonización y principio favor libertatis, adhesión a los instrumentos del Consejo de Europa, efectividad (de la Carta de la UE) versus medidas de austeridad.

\begin{abstract}
The author argues that the formal recognition of fundamental rights as common foundations of the EU through the reference to the Charter of Fundamental Rights in the Lisbon Treaty (making that document legally binding and, therefore, elevating the Charter to the same legal value as the Treaties) has provided for more constitutional appearance to the EU, but not for a more generous level of protection and enjoyment of citizenship. Indeed, together with the noninclusion of specific guarantees, different unacceptable asymmetries have been introduced in the EU Charter, such as the breach of the principle of indivisibility (civil and social rights are not treated on an equal footing) or the presumed exclusion of different countries (Czech Republic, Poland and United Kingdom) from the applicability of the EU Charter. In this context, holding that the formulation of fundamental rights in the EU Charter cannot imply a narrower conception than that developed by the Court of Justice through its human rights jurisprudence (as a part of the general principles of Community law), the essay contains arguments to overcome these asymmetries by emphasizing the necessity of positive will in order to strengthen judicial dialogue on the basis of the EU Charter clauses which promote multilevel protection and favor libertatis principle. Finally, the author suggests that exploiting these synergies and taking into account other European human rights instruments will enhance the position of the Charter of Fundamental Rights even within the EU framework (e.g. against the austerity measures launched by the Troika) and, therefore, this will improve the efficiency and democratic legitimacy of the Union as well as the coherence of its action.

Keywords: Indivisible Fundamental Rights, judicial dialogue and synergies, harmonization and favor libertatis principle, accession to Council of Europe instruments, effectiveness (of the EU Charter) versus austerity measures.
\end{abstract}




\section{Introducción: rememorando la evolución de la consagración jurídica de los derechos fundamentales como salto cualitativo de apariencia constitucional en la UE}

De entrada, y dada la existencia de centenares de contribuciones científicas dedicadas a la posición y evolución de los derechos fundamentales en la construcción de la UE, es menester no engrosar esa bibliografía con un repaso meramente descriptivo de ese decurso ${ }^{1}$. Bastará, por ende, sintetizar que la consagración de los derechos fundamentales ha quedado visualizada como un tránsito desde su consideración judicial como principios generales del Derecho comunitario hacia su formalización normativa como texto fundacional a través de la CDFUE. Pero, sobre todo, es menester analizar con tono crítico el alcance e impacto de dicho tránsito.

En efecto, hasta la vigencia de la CDFUE ganada el 1 de diciembre de 2009 a través del Tratado de Lisboa, las fases de esa consagración de los derechos fundamentales han venido marcadas paralelamente:

- De un lado, por su papel más o menos relegado en los Tratados fundacionales y sus reformas, que han convivido con declaraciones de derechos y libertades programáticas o de soft-law y con actos de Derecho derivado o secundario que explícitamente se han plasmado o inspirado la elaboración de la CDFUE teniendo en cuenta en mayor o menor medida los dos instrumentos emblemáticos del Consejo de Europa [el Convenio Europeo de Derechos Humanos (CEDH) y la Carta Social Europea (CSE)];

- Y, de otro lado, por una labor pretoriana del Tribunal de Justicia de Luxemburgo, ora autónoma sustentada en los principios generales, ora más o menos atenta a la conformidad con el CEDH y la jurisprudencia del Tribunal Europeo de Derechos Humanos (TEDH), lo que queda confirmado mediante el art. 6.3 TUE.

Por otra parte, y teniendo en mente asimismo el grueso de publicaciones sobre la elaboración y el valor de la CDFUE, es preciso igualmente examinar de modo crítico su alcance real, lo cual significa detenerse a reflexionar si la CDFUE ha incrementado la legitimidad democrática de la UE, como input y como output:

${ }^{1}$ Para un resumen evolutivo, JIMENA QUESADA, L., Sistema europeo de derechos fundamentales, ed. Colex, Madrid, 2006, en particular los capítulos séptimo [«La protección de los derechos fundamentales en la UE (I): hacia un catálogo constitucional de derechos y libertades» (pp. 151 y ss.)] y octavo [«La protección de los derechos fundamentales en la UE (II): los concretos mecanismos de tutela» (pp. 187 y ss.)]. 
- En cuanto a lo primero, cabe cuestionarse si la CDFUE se elaboró más bien desde los clásicos parámetros de «despotismo ilustrado» y de cierto «academicismo» que vienen caracterizando la aprehensión del Derecho de la Unión Europea, esto es, con distanciamiento respecto de la ciudadanía. Efectivamente, a través del método de la Convención, tanto en el caso de la CDFUE como en el supuesto más amplio del frustrado Tratado constitucional de 2004, se encauzó un proceso participativo hasta entonces desconocido en la construcción europea (con relevante participación de organizaciones de la sociedad civil). Ello no obstante, esa legitimidad democrática parece haber sido más aparente que real';

- Con relación a lo segundo, es necesario interrogarse acerca de si la efectividad de la CDFUE es verdaderamente percibida por la ciudadanía, o más bien ha seguido alimentando otras preocupaciones «ilustradas» $\mathrm{y}$ «académicas» que, sobre ser ineludibles (verbigracia, la manida adhesión de la UE al CEDH), han resultado obsesivas en la clase dirigente y en la academia, sin reparar en la vigencia cotidiana de los derechos. Desde esta óptica, la mayor apariencia constitucional seguramente tenga más de lo primero, de apariencia, pues las pretendidas vestes constitucionales casan mal con la disociación entre las normas y la realidad.

A las citadas cuestiones e interrogantes persiguen responder los epígrafes que siguen, con propuestas y críticas constructivas guiadas transversalmente por otras tantas insoslayables incógnitas: ¿Ha ganado la Europa de los derechos humanos con el nuevo método de construcción normativa, en lugar de judicial, de los derechos fundamentales? ¿Acaso la clásica prevalente Europa de los mercaderes, con la crisis económica, haya relegado aún más la Europa de los derechos humanos? En realidad, ni la CDFUE debería significar una neutralización del papel del TJUE, ni la crisis económica habría de comportar una crisis de derechos humanos en la UE. Posiblemente deberá incidirse en una apuesta menos ilustrada y académica, y más ciudadana y pedagógica a favor de la ciudadanía, para que la prevalencia del credo económico originario de las Comunidades Europeas (lamentada finalmente por Jean Monnet, quien incidió en la cultura) se vea compensado con mayor formación y conciencia ciudadanas ${ }^{3}$.

2 JIMENA QUESADA, L., «La Carta de los Derechos Fundamentales de la UE: rango legal y contenidos sustantivos», Cuadernos Europeos de Deusto, n. ${ }^{\circ} 40,2009$, pp. 63-83.

3 Con tal filosofía, PÉREZ DE LAS HERAS, B., «Derechos fundamentales y ciudadanía en la Constitución Europea: La ciudadanía de la Unión en la Constitución para Europa», Noticias de la Unión Europea, n. ${ }^{\circ}$ 250, 2005. 


\section{La CDFUE ante el dilema estatuto formal-real efectividad}

\section{Un catálogo, al menos, triplemente asimétrico}

A) Visibilidad formal versus indivisibilidad material

De un primer acercamiento a la CDFUE aparentemente habría mediado unanimidad en encontrar plausible el grado de visibilidad formal que ganaban los derechos fundamentales en la UE. Cabalmente, en el Preámbulo de la propia CDFUE se afirma la necesidad de dotarlos «de mayor proyección en una Carta» (versión oficial integrada en el Tratado de Lisboa; la versión oficial proclamada en 2000 se refería a dotarlos «de mayor presencia en una Carta»), que a título de ejemplo equivale en las versiones francesa e inglesa a hacerlos «plus visibles dans une Charte» $\mathrm{o}$ «more visible in a Charter», respectivamente.

Por añadidura, esa mayor visibilidad formal condujo a aplaudir a los redactores, entre ellos dirigentes ilustrados e ilustres académicos, por su aparente grado de generosidad al incluir un buen número de derechos y de innovación al sistematizarlos, concretamente con una técnica novedosa consistente en agruparlos en torno a una serie de valores o nociones que rubrican los seis primeros títulos: «dignidad» (Título I, arts. 1 a 5); «libertades» (Título II, arts. 6 a 19); «igualdad» (Título III, arts. 20 a 26); «solidaridad» (Título IV, art. 27 a 38); «ciudadanía» (Título V, arts. 39 a 46), y «justicia» (Título VI, arts. 47 a 50). Permítaseme, empero, no hacer gala de tamaño entusiasmo, mostrando más bien mis críticas.

Pues bien, al margen de lamentar que ese carácter generoso e innovador no se extendiera a las garantías (volveré sobre ello en el epígrafe siguiente), incluso en el plano formal algunos derechos han sido reconocidos con una redacción sesgada pese a extraerse de otros instrumentos, como expresamente se justifica en las Explicaciones anejas ${ }^{4}$. Esa asimetría formal se comprueba asimismo al ubicarse otros derechos fuera del catálogo de la CDFUE 5 .

Peor aún: el loable título global de la Carta etiquetando de «derechos fundamentales» a todos los reconocidos en ella (más acorde con el lenguaje y la estética constitucionales) comporta una visibilidad formal que,

${ }^{4}$ Verbigracia, la formulación del art. 25 CDFUE (derechos las personas mayores) es más genérico y aséptico que la fuente inspiradora mencionada en las Explicaciones (el art. 23 CSEr), que incluye no sólo la faceta participativa, sino también y sobre todo la vertiente de protección social de dichas personas.

5 Por ejemplo, derecho de los ciudadanos de formular propuestas de iniciativa legislativa (nuevo art. 11 TUE, incluido entre las disposiciones sobre los principios democráticos -Título II-). 
a continuación, se ve truncada al hacer irrumpir formalmente en el texto una quiebra del principio de indivisibilidad mediante una inaceptable dicotomía entre «derechos» y «principios» establecida en su Preámbulo o

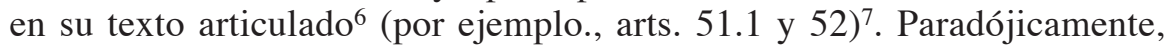
mientras el título genérico de la CDFUE, e incluso la sistematización de los derechos efectuada con arreglo a los valores que rubrican cada título, parecen estar apostando por el principio de indivisibilidad, interdependencia e igual importancia de todos los derechos, la citada dicotomía evoca una excepción sustancial a dicho principio mediante la jerarquización o categorización de ellos, en contradicción incluso con la idea de «valores indivisibles y universales de la dignidad humana» explícitamente consignada en el Preámbulo.

Por lo demás, al margen de otras asimetrías que retomaré seguidamente al abordar la problemática de las garantías, el punto más positivo de la CDFUE tal vez radique, no tanto en los derechos sustanciales (cuya equivalencia - e incluso con un redacción más avanzada - ya encontramos en otros instrumentos internacionales de derechos humanos), sino en los derechos procedimentales o instrumentales para la defensa de otros derechos de las personas ${ }^{8}$, como es el caso de la novedosa formulación del derecho a una buena administración (art. 41 CDFUE, cuya redacción se ha inspirado en gran medida en la tarea llevada a cabo por el Defensor del Pueblo Europeo y el Código europeo de buena conducta administrativa impulsado por él ${ }^{9}$ ) o el «derecho a una buena justicia» (art. $47 \mathrm{CDFUE}^{10}$ ).

${ }^{6}$ Semejante técnica redactora recuerda a la desafortunadamente utilizada por el constituyente español de 1978, calificando a todos los reconocidos en el Título I de «derechos fundamentales»y, a renglón seguido, «rebajando» algunos de ellos a la categoría de «principios rectores de la política social y económica».

7 Sobre este punto, la crítica de JACQUÉ, J.P., «La Carta de los derechos fundamentales de la Unión Europea», Observatorio de la Globalización, Serie General, n. ${ }^{\circ}$ 1, noviembre 2000, http://www.ub.es/obsglob/Seriegeneral.html (final epígrafe 4 de la conferencia).

8 Acúdase a BIFUlCO, R., CARTABIA, M., CELOTTO, A. (eds.), L’Europa dei diritti. Commento alla Carta dei diritti fondamentali dell'Unione europea, ed. Il Mulino, Padova, 2001, entre otras, pp. 319 y ss. para los derechos de defensa en el proceso judicial.

9 SÖDERMANN, J., «El derecho fundamental a la buena administración», Gaceta Jurídica de la Unión Europea y de la Competencia, n. ${ }^{\circ}$ 214, julio/agosto 2001. De manera más exhaustiva, TOMÁS MALLÉN, B. S., El derecho fundamental a una buena administración, ed. INAP, Madrid, 2004.

${ }^{10}$ BRAYBANT, G., La Charte des droits fondamentaux de l'Union européenne, Paris, Éditions du Seuil, 2001, p. 235. También apuntan esta relación entre los arts. 41 y 47 FERRARI BRAVO, L., DI MAJO, F., RIZZO, A., Carta dei diritti fondamentali dell'Unione europea commentata con la giurisprudenza della Corte di giustizia CE e della Corte europea dei diritti dell'uomo e con i documenti rilevanti, ed. Giuffrè Editore, Milano, 2001, p. 178. 
B) Reconocimiento de derechos sin garantías jurisdiccionales

$\mathrm{Si}$, evidentemente, la afirmación según la cual los derechos valen tanto como sus garantías no es en absoluto retórica, es claro que la mayor asimetría presente en la CDFUE consiste en haber prescindido de un mecanismo específico de tutela. En cualquier caso, no merece la pena incidir en ello lamentándose retrospectivamente sobre lo que pudo ser y no fue, siendo suficiente con reiterar que la cuestión de las garantías jurisdiccionales no quedó diseñada a la medida de la ciudadanía en la CDFUE ${ }^{11}$, que rechazó la posibilidad de un recurso de amparo ante el TJUE ${ }^{12}$.

Con tal espíritu, en el terreno jurisdiccional, la mirada prospectiva debe fijarse en la optimización de las posibilidades garantistas ofrecidas por el Título VII CDFUE («Disposiciones generales que rigen la interpretación y la aplicación de la Carta», arts. 51 a 54) y especialmente de sus arts. 52.3 y 53 (apartado III, infra). Bajo tal ángulo, no convendría exagerar la inexistencia de un recurso de amparo, a tenor del altísimo porcentaje de inadmisiones, superior al noventa por ciento, que nos muestra la experiencia del TEDH o del propio Tribunal Constitucional español; piénsese en que buena parte de los países de la Unión Europea no han otorgado competencia a sus respectivas jurisdiccionales constitucionales para conocer acciones individuales de tutela, sin que ello signifique que el estado de respeto de los derechos fundamentales sea más precario.

En estas mismas coordenadas, deben consecuentemente potenciarse otras garantías, tanto normativas (a las que apela el art. 52.5 de la Carta, asumida ya con anterioridad a su entrada en vigor como referente de técnica legislativa ${ }^{13}$ ) como no jurisdiccionales: entre estas últimas, la CDFUE realza la institución del Defensor del Pueblo Europeo (art. 43), sin olvidar

11 RALLO LOMBARTE, A., «Las garantías jurisdiccionales de los Derechos Fundamentales reconocidos en la Carta de Derechos Fundamentales de la Unión Europea», en ÁLVAREZ CONDE, E., y GARRIDO MAYOL, V. (dirs.), Comentarios a la Constitución Europea, libro II, ed. Tirant lo Blanch/Consejo Jurídico Consultivo de la Comunitat Valenciana, Valencia, 2004, pp. 1629-1652.

12 Vid. SANZ CABALlERO, S., «Algunos signos de déficit democrático en el Tratado Constitucional Europeo y en su Carta de Derechos Fundamentales», Colección Escuela Diplomática, n. ${ }^{\circ}$ 9, 2005, p. 279. Ese déficit ya subrayado antes por PI LLORENS, M., La Carta de los derechos fundamentales de la Unión Europea, ed. PUB, Barcelona, 2001, p. 104.

13 Efectivamente, la CDFUE ha sido asumida como un elemento transversal para el desarrollo del conjunto de actividades de la UE, especialmente las legislativas, como se desprende del Report on compliance with the Charter of Fundamental Rights in the Commission's legislative proposals: methodology for systematic and rigorous monitoring [Committee on Civil Liberties, Justice and Home Affairs, Rapporteur: Johannes Voggenhuber, European Parliament, 12.2.2007 (Session document, FINAL A6-0034/2007)]. 
el papel nada despreciable que está jugando la Agencia de los Derechos Fundamentales de la UE.

\section{C) Espacio único de ciudadanía europea versus desigualdad territorial}

Ante todo, conviene dejar sentado que la consagración de los derechos fundamentales se ha inscrito como parte integrante de los textos fundacionales a través del Tratado de Lisboa y, por tanto, al máximo nivel jerárquico-normativo. Dicho rango no se ve en absoluto alterado por la circunstancia de haberse acogido en el Tratado de Lisboa la opción técnica más débil de las propuestas en el antecedente Anteproyecto constitucional de 28 de octubre de $2002^{14}$, sin que la solución retenida de la técnica del reenvío ${ }^{15}$ (similar a la que existe en la Constitución francesa vigente de 1958 con respecto a la Declaración de derechos del hombre y del ciudadano de 1789 o al catálogo de derechos de la previa Constitución gala de 1946) resulte menos contundente que la técnica de la integración en el texto articulado del Tratado (técnica utilizada en este caso por la mayoría de Constituciones nacionales, como sucede con el Título I de la Carta Magna española de 1978).

Correlativamente, la inscripción a ese mismo nivel jerárquico-normativo del Protocolo $n .^{\circ} 30$ sobre la aplicación de la CDFUE a Polonia y al Reino Unido (extendido posteriormente a la República Checa) resulta preocupante. Las exégesis posibles del alcance de dicho Protocolo podrían abarcar desde aquellas negativas que lo concebirían como un auténtico Protocolo de salida (opt-out) peligrosamente evocador de la «Europa de las velocidades» y otras denominaciones similares («Europa a geometría variable», etc.); hasta aquellas otras más optimistas que lo considerarían en la práctica más cercano a una «Declaración» que reproduce las mismas cautelas explicitadas por la propia CDFUE con relación a su alcance, en el sentido de no ampliar las competencias de la Unión ni habilitar a los órganos internos para utilizar la CDFUE cuando no apliquen Derecho de la Unión.

${ }^{14}$ A tenor de dicho Anteproyecto (art. 6): la primera opción consistía en que «podría hacerse referencia a la Carta», para lo cual se añade de manera conexa que el citado art. 6 «podrá estar inspirado en el art. 6 del Tratado de la Unión Europea»; según la segunda opción planteada por el art. 6 del Anteproyecto constitucional, «podría establecerse el principio de la integración de la Carta, incorporando el articulado de ésta en otra parte del Tratado o en un protocolo especial anejo a la Constitución»; y, de conformidad con la tercera opción, más contundente, «podría integrarse el articulado completo de la Carta».

15 Art. 6.1 TUE: «1. La Unión reconoce los derechos, libertades y principios enunciados en la Carta de los Derechos Fundamentales de la Unión Europea de 7 de diciembre de 2000, tal como fue adaptada el 12 de diciembre de 2007 en Estrasburgo, la cual tendrá el mismo valor jurídico que los Tratados». 
A mi modo de ver, esta segunda parece la conclusión hermenéutica más acertada, de suerte que el Protocolo mencionado no añadiría ni restaría nada al rango legal y alcance jurídico de la CDFUE, más allá de la lectura política que, sin duda, este tipo de Protocolos sugiere de cara a la opinión pública (el electorado) nacional y, en su caso, europea: Polonia y el Reino Unido expresan en el Protocolo su deseo «de que se precisen determinados aspectos de la aplicación de la Carta», pero no el de excluir la aplicación de ella. En apoyo de esa lectura sobre el efecto inútil ${ }^{16} \mathrm{o}$ inefectivo ${ }^{17}$ de dicho Protocolo entiendo que militan, al menos, los siguientes argumentos:

- Si, de conformidad con el art. 6 TUE, la CDFUE ostenta el mismo valor jurídico que los Tratados y forma parte integral del Tratado de Lisboa, una «cláusula de salida» se perfilaría como contraria al objeto y fin del tratado de Lisboa y, consiguientemente, admitiría una lectura equivalente a una reserva prohibida por la Convención de Viena de 1969 sobre el Derecho de los Tratados; adicionalmente, rompería la proclamada dinámica maximalista a favor de los derechos humanos con la que pretende dotarse de credibilidad y legitimidad a los Tratados europeos ${ }^{18}$, tanto más cuanto que el art. 6 TUE y la CDFUE representarían cláusulas homogéneas compartidas por todos los Estados miembros ${ }^{19}$ sin posibilidad de excepciones heterogéneas ${ }^{20}$.

- La aceptación de semejantes cláusulas de salida relativas a la CDFUE no acarrearía una mera oposición formal al mayor logro sustancial representado por la Parte II del fallido Tratado constitucional de $2004^{21}$, sino que comportarían un ataque frontal al clásico objetivo

${ }^{16}$ ZILLER, J., Il nuovo trattato europeo, ed. Il Mulino, Bologna, 2007, p. 177.

17 FERNÁNDEZ TOMÁS, A.F., «La Carta de Derechos Fundamentales de la Unión Europea tras el Tratado de Lisboa. Limitaciones a su eficacia y alcance generadas por el Protocolo para la aplicación de la Carta al Reino Unido y Polonia», en MARTÍN Y PÉREZ DE NANCLARES, J. (coord.), El Tratado de Lisboa: la salida de la crisis constitucional, ed. Iustel, Madrid, pp. 119-149.

18 BREMS, E., «Human Rights: Minimum and Maximum Perspectives», Human Rights Law Journal, n. ${ }^{\circ} 9$ (3), 2009, p. 372.

19 MANGIAMELI, S., «La cláusula de homogeneidad en el Tratado de la Unión Europea y en la Constitución europea», Revista de Derecho Político, n. ${ }^{\circ}$ 67, 2006, pp. 409-452.

20 BELLAMY, R., Judicial review in review: A four-part defense of legal constitutionalism. A review essay on Political Constitutionalism, ed. Cambridge University Press, Cambridge, 2007, p. 50.

${ }^{21}$ BONNEMAISON, J.L., «L'identité européenne à travers la Charte des droits fondamentaux de l'Union européenne», Civitas Europa, n. ${ }^{\circ}$ 21, 2008, p. 173. Más ampliamente, BURGORGUE-LARSEN, L., y LEVADE, A. (dirs.), Traité établissant une Constitution pour l'Europe, tomo 2: La Charte des Droits Fondamentaux de l'Union, ed. Bruylant, Buxelles, 2005. 
de los Tratados comunitarios de garantizar los derechos fundamentales como principios generales inspirados asimismo en las tradiciones constitucionales comunes a los Estados miembros ${ }^{22}$ y en el $\mathrm{CEDH}^{23}$, según la jurisprudencia del TJUE ${ }^{24}$.

- Si, en la misma línea, la CDFUE reafirma, según su Preámbulo, «dentro del respeto de las competencias y misiones de la Unión, así como del principio de subsidiariedad, los derechos que emanan, en particular, de las tradiciones constitucionales y las obligaciones internacionales comunes a los Estados miembros, del Convenio Europeo para la Protección de los Derechos Humanos y de las Libertades Fundamentales, las Cartas Sociales adoptadas por la Unión y por el Consejo de Europa, así como de la jurisprudencia del Tribunal de Justicia de la Unión Europea y del Tribunal Europeo de Derechos Humanos», y los tres países controvertidos (Polonia, Reino Unido y República Checa) participan de esas tradiciones comunes y esos instrumentos internacionales, la cláusula de salida revelaría una clara inconsistencia por su parte ${ }^{25}$.

- En análogo sentido, si justamente por ello mismo la CDFUE pudo ser utilizada como fuente de inspiración por diversas jurisdicciones nacionales y europeas desde su proclamación solemne en diciembre de 2000 y, por tanto, con anterioridad a su vigencia en diciembre de 2009, la cláusula de salida carecería de sentido en términos jurídicoprácticos ${ }^{26}$.

${ }^{22}$ El enfoque constitucional de los Estados miembros en el ámbito exterior en ocasiones ha sido compensado por la jurisprudencia del TJUE en temas controvertidos (garantías procedimentales ante medidas antiterroristas con listados de individuos y sanciones impulsadas desde Naciones Unidas como el bloqueo o congelación de cuentas bancarias): véase la STJUE de 3 de diciembre de 2008 en los casos Yassin Abdullah Kadi y al Barakaat International Foundation c. Consejo y Comisión (C-402/05 P and C-415/05). Vid. ECKES, Ch., «Test Case for the Resilience of the EU's Constitutional Foundations», European Public Law, ed. Kluwer Law International, n. ${ }^{\circ} 15$ (3), 2009, p. 378, así como SANTOS VARA, J., «El control judicial de las sanciones contra Al-Qaeda y los talibanes en la Unión Europea: ¿un desafío a los poderes del Consejo de Seguridad?», Revista de Derecho Comunitario Europeo, n. ${ }^{\circ} 32,2009$, pp. 91-120.

${ }^{23}$ GOLDSTON, J.A., «Achievements and Challenges - Insights from the Strasbourg Experience for Other International Courts», European Human Rights Law Review, n. ${ }^{\circ} 5$, 2009, p. 603. Un enfoque matizado en TAPPER, C., «The Law of Evidence and the Rule of Law», The Cambridge Law Journal, n. ${ }^{\circ}$ 68, 2009, p. 81.

${ }^{24}$ CARTABIA, M., «L'universalità dei diritti umani nell'età dei nuovi diritti», Quaderni costituzionali, n. ${ }^{\circ} 3,2009$, p. 544.

25 PALOMBELLA, G., «The rule of law beyond the state: Failures, promises and theory», International Journal of Constitutional Law, n. ${ }^{\circ} 7$ (3), 2009, pp. 442-467.

${ }^{26}$ DÍEZ-PICAZO, L.M., «Glosas a la nueva Carta de Derechos Fundamentales de la UE», Tribunales de Justicia, n. ${ }^{\circ}$ 5, 2001, p. 26. 
- Si la UE debe legislar en coherencia con la CDFUE (y, en la praxis, las instituciones europeas han ido adoptando Reglamentos y Directivas inspirándose en ella), implicaría una clara incoherencia de acción no aceptar el Derecho primario de la UE (la CDFUE) y, en cambio, someterse a esas fuentes de Derecho secundario ${ }^{27}$.

\section{La posición del TJUE ante la CDFUE: la diferencia cualitativa de su labor pretoriana con o sin base normativa}

Por lo pronto, contrasta el reconocimiento de la labor pretoriana del TJUE en materia de derechos fundamentales con la timidez de su actividad jurisdiccional con relación a la CDFUE. Esa actitud tímida se ha manifestado en la tardanza del Tribunal de Justicia a la hora de citar siquiera la CDFUE antes de su vigencia, cuando diversamente algunos Tribunales nacionales (jurisdicciones constitucionales incluidas) e incluso los Abogados Generales y el entonces Tribunal de Primera Instancia la habían citado.

La mera cita indudablemente era modesta (pero aplaudida con entusiasmo por la doctrina, conformista con semejante exigencia estética - como el congratularse doctrinalmente por constatar que el Tribunal de Justicia introducía el adjetivo «constitucional» en algún pronunciamientocomo si ese prurito academicista facultara para olvidarse de lo realmente importante, su potencialidad como instrumento garantista) y de hecho, auguraba una ulterior posición poco entusiasta del TJUE con respecto a la CDFUE incluso tras su vigencia en diciembre de 2009. En estas condiciones, cobra sentido la pregunta acerca de si la consagración normativa de la CDFUE en los tratados fundacionales ha mejorado realmente la protección de los derechos fundamentales.

El diagnóstico no parece demasiado halagüeño si, por ejemplo, se pone el foco de interés en la conciliación entre las clásicas libertades económicas y los derechos sociales, puesto que estos últimos ya habían admitido algún pronunciamiento, siquiera aislados, que los incluía entre los derechos fundamentales integrantes a su vez de los principios generales del Derecho comunitario ${ }^{28}$. Resta entonces por comprobar si, tras la vigencia del Tratado

27 Se ha esgrimido así que dicho Protocolo n. 30 genera gran inseguridad jurídica: DE SCHUTTER, O., «Les droits fondamentaux dans l'Union européenne», Journal de droit européen, n. ${ }^{\circ} 148,2008$, p. 127.

${ }_{28}$ MORIJN, J., «Balancing Fundamental Rights and Common Market Freedoms in Union Law: "Schmidberger" and the "Omega" in the Light of the European Constitution», European Law Journal, n. ${ }^{\circ} 12$ (1), 2006. 
de Lisboa, el TJUE se va a mostrar excesivamente circunspecto en lo atinente a los derechos sociales o, al contrario, va a ser coherente con el principio de indivisibilidad superando la simple o secundaria catalogación de éstos como restricciones o límites a los derechos fundamentales, o como meros «principios» y no verdaderos «derechos».

En otras palabras, ¿accederá el TJUE a rebajar los derechos sociales de la categoría de principios generales (derechos fundamentales) a la de principios «rectores»? Dicha posición «a la baja» representaría una criticable asimetría jurisprudencial paralela al estatuto asimétrico normativo de la CDFUE: así, la CSE del Consejo de Europa es mencionada en el Preámbulo CDFUE, mientras se suprime toda referencia a ella en su texto articulado, pese a que en las Explicaciones queda claro que tanto la CSE de 1961 como, sobre todo, la CSE revisada de 1996, han impregnado la redacción de buena parte de las disposiciones de la CDFUE. Al mismo tiempo, llama la atención que el Tratado de Lisboa incluya una referencia a la CSE (pero a la de 1961, no a la revisada de 1996) en el Preámbulo del TUE y en el art. 151 del TFUE (art. 136 TCE, en el Título X referente a la «política social»).

Semejante actitud resulta harto cicatera, por no hablar del ostracismo reservado a la instancia máxima interpretativa de la CSE, el Comité Europeo de Derechos Sociales (CEDS), no citado en la CDFUE (ni en el Preámbulo, ni el texto articulado ni siquiera en las Explicaciones anejas) y desconocido asimismo hasta la fecha por el TJUE, a diferencia del TEDH (sobre lo cual se volverá en el apartado III, infra), a pesar de la llamada explícita de la CDFUE a la sinergia entre los diversos niveles de protección $(\text { art. 53) })^{29}$.

En suma, por un lado, la propia CDFUE parece haber revelado mayor preocupación e interés por el juego de la distribución de competencias que por la garantía de los derechos fundamentales; y, por otro lado, los principios generales realzados por la clásica jurisprudencia pretoriana del Tribunal de Justicia todavía pueden ser útiles y estar llamados a jugar un papel apreciable, no sólo ante las pretendidas exclusiones (motivadas significativamente por los derechos sociales, etiquetados «de solidaridad», sobre todo en el caso de Polonia) sino también ante la ya reseñada dicotomía entre «derechos» $\mathrm{y}$ «principios». ¿Acaso la consagración normativa habría paradójicamente debilitado el legado jurisprudencial?

29 Acaso ese titubeante y asimétrico diseño predominante en la CDFUE, concebida en teoría como elemento sustancial y fundamental (como parte dogmática de una pretendida «Constitución europea» material) del Tratado de Lisboa, justifique la crítica definición de éste como «contrarreforma constitucional», según el lúcido análisis de MARISCAL, N., Más allá de Lisboa: Horizontes europeos, ed. Tecnos, Madrid, 2010. 


\section{Retos pendientes, pese a la CDFUE: armonización interpretativa, armonización normativa y crisis económica}

\section{La voluntad jurisdiccional positiva del TJUE al acometer los contenciosos paralelos a escala internacional}

Pese a la existencia de contenciosos paralelos que se han saldado con divergencias entre el TJUE y el $\mathrm{TEDH}^{30}$, que ciertamente son susceptibles de seguir aflorando (a expensas de la operatividad de la adhesión de la UE al CEDH) en ámbitos concurrentes ${ }^{31}$, tanto la Corte de Luxemburgo como la de Estrasburgo han intentado ofrecer una imagen de colaboración y enriquecimiento mutuo: la prueba vendría suministrada por la idea de interpretación conforme al CEDH y por las referencias frecuentes a la jurisprudencia del TEDH por parte del TJUE (lo que se ha explicitado en la propia CDFUE) y, paralelamente, por la presunción de conformidad de la legislación de la UE con el CEDH o de equivalencia de estándares europeos asumida por el TEDH en su jurisprudencia Bosphorus ${ }^{32}$.

En contraste con ello, las soluciones divergentes pueden emerger con mayor facilidad entre el TJUE y el CEDS, debido no únicamente al reseñado estatuto asimétrico de la CDFUE en detrimento de los derechos socia-

${ }^{30}$ Por ejemplo, ya en el siglo pasado, en los años ochenta la doctrina divergente en materia de inviolabilidad del domicilio [extensible a las personas físicas y jurídicas para el órgano jurisdiccional con sede en Estrasburgo (caso Niemietz c. Alemania de 16 de diciembre de 1992), y sólo a las primeras para el sedente en Luxemburgo (caso Hoechst c. Comisión de 21 de septiembre de 1989)]; o en los años noventa la controversia acerca de la información y la libre prestación de servicios en materia de aborto en Irlanda (STJUE de 4 de octubre de 1991 pronunciada en el caso Society for the Protection of Unborn Children Ireland Ltd c. Stephen Grogan y otros, y STEDH de 29 de octubre de 1992 dictada en el caso Open Door y Dublin Well Woman c. Irlanda).

${ }^{31}$ El cuadro de potenciales divergencias se ha ampliado si se tiene en cuenta la comunitarización del «acervo de Schengen», que ha propiciado que el TJUE se vea llamado a pronunciarse sobre materias relacionadas con el actual espacio de libertad, seguridad y justicia de la UE contempladas asimismo en el CEDH (a título de ejemplo, STEDH de 13 de febrero de 2001 dictada en el caso Krombach c. Francia o STJUE 11 de febrero de 2003 pronunciada en el caso Hüseyin Gözütok y Klaus Brügge). En este orden de cosas, la solución de demandar a todos los Estados miembros de la Unión al no poder jurídica y formalmente formular la queja frente a ésta por no ser Parte en el CEDH, no se ha mostrado óptima: al menos dos sentencias del TEDH lo corroboran (una, la dictada el 23 de mayo de 2002 en el caso Segi y otros c. Austria, Bélgica, Dinamarca, Finlandia, Francia, Alemania, Grecia, Irlanda, Italia, Luxemburgo, Países Bajos, Portugal, España, Suecia y Reino Unido; la otra, la dictada el 10 de marzo de 2004 en el caso DSR-Senator Lines GMBH contra, nuevamente, los quinces países miembros de la Unión Europea en aquel momento). Véase asimismo la STEDH de 18 de febrero de 1998, caso Matthews c. Reino Unido.

32 STEDH (Gran Sala) Bosphorus Hava Yollari Turzim ve Ticaret Anonim Sirketi c. Irlanda de 30 de junio de 2005. 
les sino asimismo al «riesgo de que el sistema de derechos estatal se revise a partir de la perspectiva economicista que postula la Constitución material de los Tratados comunitarios, marco de referencia ineludible para el propio TJUE» ${ }^{33}$; y, al propio tiempo, el Comité Europeo no ha dado por buena esa presunción de conformidad de la legislación de la UE con la CSE (por ejemplo, Reclamación n. ${ }^{\circ}$ 56/2009, Confédération française de l'Encadrement CFE-CGC, Decisión de fondo de 23 de junio de 2010, $\S \S 29-40)$. Veamos dos ejemplos.

1. $\left.{ }^{\circ}\right)$ Tanto el CEDS como el TJUE se han pronunciado sobre la duración del tiempo legal de trabajo y la noción de trabajo efectivo, por referencia a la legislación francesa relativa a la no equiparación del tiempo de presencia que está el trabajador a disposición del empleador en el centro de trabajo («régime d'astreinte» o «guardia localizada») y del tiempo de trabajo con actividad laboral ordinaria. El Comité determinó en su Decisión de fondo de 8 de diciembre de 2004 sobre la Reclamación colectiva n. ${ }^{\circ}$ 22/2003 (caso Confederación General del Trabajo c. Francia), que la asimilación de los períodos de presencia con los períodos de descanso constituye una violación del art. 2 (apartados 1 y 5) de la CSE (derecho a unas condiciones de trabajo equitativas).

A similar conclusión llegó el Tribunal de Justicia de Luxemburgo prácticamente un año después, en el caso Abdelkader Dellas (asunto C-14/04), resuelto mediante Sentencia de 1 de diciembre de 2005, pero sin mencionar en absoluto la Decisión del CEDS, basándose exclusivamente en el Derecho de la Unión (en particular, en la Directiva 93/104/CE del Consejo, de 23 de noviembre de 1993, relativa a determinados aspectos de la ordenación del tiempo de trabajo). Pero, ¿qué habría ocurrido en caso de decisiones contradictorias o divergentes? La hipótesis no es inimaginable, y se ha verificado recientemente, como se ilustra con el segundo ejemplo.

2. $\left.{ }^{\circ}\right)$ El Tribunal de Estrasburgo ha enfocado la conciliación de las libertades económicas y derechos sociales como la acción colectiva (en conflictos de gran repercusión que han tenido como telón de fondo, entre otros aspectos, el abanderamiento ficticio de buques que recuerda la deslocalización y evitación de normativa laboral más favorable) otorgando prioridad a

33 DE MIGUEL BÁRCENA, J., «La justicia constitucional en la teoría de la Constitución europea», en TAJADURA, J. y DE MIGUEL, J. (coords.), Justicia Constitucional y Unión Europea, ed. Centro de Estudios Políticos y Constitucionales, Madrid, 2008, p. 317. Interesante también la llamada de atención de BELORGEY, J.M., «Les droits sociaux face à la mondialisation: peut-on les mantenir et les réaliser?, en ALIPRANTIS, N. (ed.), Les droits sociaux dans les instruments européens et internationaux. Défis à l'échelle mondiale, ed. Bruylant, Bruxelles, 2009, p. 412: en el nivel internacional de protección de los derechos sociales se deben «homogeneizar las exigencias y evitar los juegos a la baja». 
las primeras y enfocando como meras restricciones (no como derechos) los segundos (así, las SSTJUE dictadas en los asuntos Viking Line, C-438/05, de 11 de diciembre de 2007, Laval un Partneri, C-341/05, de 18 de diciembre de 2007, Rüffert, C-346/06, de 3 de abril de 2008, o Comisión c. Luxemburgo, C-319/06, de 19 de junio de 2008).

En clara oposición, en la Decisión de fondo de 3 de julio de 2013 sobre la reclamación n. ${ }^{\circ}$ 85/2012 (Confederación General del Trabajo de Suecia y Confederación General de ejecutivos, funcionarios y empleados c. Suecia, en la que los sindicatos reclamantes denunciaban explícitamente que los cambios producidos en la legislación sueca tras la Sentencia Laval del TJUE habrían restringido la libertad sindical y la negociación colectiva) el CEDS ha concluido una violación de los apartados 2 y 4 del art. 6 (derecho a la negociación colectiva), así como del art. 19.4 (derecho de los trabajadores migrantes y sus familias a la protección y asistencia, concretamente a recibir un trato no menos favorable que los nacionales en materia de remuneración y demás condiciones laborales, y de afiliación a las organizaciones sindicales y disfrute de las ventajas ofrecidas por los convenios colectivos) de la CSE.

A la vista de dicha conclusión, y teniendo presente que los pronunciamientos mencionados del TJUE datan de fecha anterior a la vigencia de la CDFUE en diciembre de 2009, lo deseable sería un cambio de postura del Tribunal de Luxemburgo acorde con la idea de sinergia con el nivel de protección más favorable (en este caso, el de la CSE), a tenor de esa llamada a la armonización al alza prevista por el art. 53 de la propia CDFUE. Lo cual, a mayor abundamiento, sería consecuente con el hecho de que tanto la CSE de 1961 como la revisada de 1996 han sido utilizadas para la redacción de la CDFUE, según se reconoce en las Explicaciones anejas a ésta ${ }^{34}$. Confiemos a tal efecto en algún apunte posiblemente prospectivo, como la más reciente STJUE pronunciada el 15 de julio de 2010 (asunto C-271/08, Comisión Europea c. Alemania, sobre adjudicación directa de contratos, sin licitación a escala de la Unión, a entidades aseguradoras designadas en un convenio colectivo celebrado entre interlocutores sociales), en donde ya se viene a mencionar el parámetro del art. 6 (derecho a la negociación co-

${ }^{34}$ Según las Explicaciones anejas a la CDFUE, al menos siete derechos fundamentales de ella se inspiran en otros tantos de la Carta Social Europea revisada de 1996 (CSEr): el art. 23 sobre igualdad entre mujeres y hombres (se inspira en el art. $20 \mathrm{CSEr}$ ), el art. 25 sobre derechos de las personas mayores (en el art. 23 CSEr), el art. 27 sobre derecho a la información y consulta de los trabajadores en la empresa (en el art. 21 CSEr), el art. 30 sobre protección en caso de despido injustificado (en el art. 24 CSEr), el art. 31 sobre condiciones de trabajo justas y equitativas (en el art. 26 CSEr), el art. 33 sobre vida familiar y vida profesional (en el art. 27 CSEr), y el art. 34 sobre seguridad social y ayuda social (en los arts. 30 y 31 CSEr). 
lectiva) de la CSE revisada de 1996; ese ya es un paso interesante, aunque el TJUE no haya decidido todavía dar el salto de acudir a la jurisprudencia del CEDS.

\section{El diálogo judicial del TJUE con las jurisdicciones nacionales}

Sin lugar a dudas, el diálogo del TJUE con las jurisdicciones domésticas se ha mostrado más fluido con los órganos de la justicia ordinaria (más proclives a actuar como jueces «europeos» y a utilizar el mecanismo de colaboración consistente en las cuestiones prejudiciales) que con los tribunales constitucionales (más apegados a una idea «clásica» de supremacía y menos favorables a someter dudas prejudiciales a la Corte de Luxemburgo) ${ }^{35}$. Como consecuencia de ello se han producido divergencias interpretativas importantes, como la ilustrada por la transposición de la Decisión marco 2002/584/JAI sobre la orden de detención y entrega («euroorden») y la propia puesta en práctica de ese novedoso procedimiento acelerado de extradición.

En este escenario, debe traerse a colación la STJUE (Gran Sala) de 3 de mayo de 2007 (asunto C-303/05, caso Advocaten voor de Wereld VZW y Leden van de Ministerraad), mediante la que se pronuncia directamente sobre la Decisión marco relativa a la euroorden con respecto a su transposición en Bélgica; en el fallo se apuesta por no poner reparos al proceso de integración europea, declarando que el respeto de principio de legalidad de los delitos y las penas y del principio de igualdad y no discriminación no queda en entredicho y, por ende, no puede afectar a la validez de dicha Decisión marco.

De manera divergente, el Tribunal Constitucional federal alemán, mediante Sentencia de 18 de julio de $2005^{36}$, declaró la nulidad de la Ley alemana de 21 de julio de 2004 que incorporaba la euroorden por cuanto, en esencia, dicha ley no preveía la negativa a entregar a la persona reclamada cuando el delito se hubiera cometido en Alemania ni permitía interponer un recurso contra la decisión de entrega. Por su lado, el TC español venía incurriendo en una divergencia más comedida, consistente en no haber suscitado un problema genérico derivado de la transposición de la euroorden, sino en sancionar las concretas disfunciones susceptibles de merecer un otorgamiento

35 Un interesante número de contribuciones sobre ese intercambio judicial en la obra colectiva de FERRER MAC-GREGOR, E., y HERRERA GARCÍA, A. (coords.), Diálogo Jurisprudencial en Derechos Humanos. Entre Tribunales Constitucionales y Cortes Internacionales, ed. Tirant lo Blanch, Valencia, 2013.

${ }^{36}$ Bundesverfassungsgericht (BVergG, 2 BvR 2236/04, 18.7.2005). Puede accederse al texto en la dirección: http://www.bverfg.de/entscheidungen/rs20050718_2bvr223604.html. 
del amparo constitucional en supuestos específicos ${ }^{37}$. En síntesis, la posición de la jurisdicción alemana se habría fundamentado en un polémico juicio abstracto $^{38}$, mientras que el TC español ha llegado a decantarse por seguir la línea jurisprudencial europea con objeto de evitar incluso las citadas contradicciones puntuales, haciendo uso él mismo de la cuestión prejudicial ${ }^{39}$.

Por supuesto, pese a la asunción de las «tradiciones constitucionales comunes» en el entramado jurídico de la UE, los recelos de algunas jurisdicciones constitucionales y su potencial conflicto con el TJUE ya son clásicos ${ }^{40}$, especialmente con motivo de las grandes reformas de los Tratados fundacionales. No es de extrañar que la Sentencia de la Sala Segunda del Tribunal Constitucional Federal alemán de 30 de junio de 2009 avalara la constitucionalidad, en general, del Tratado de Lisboa, sin perjuicio de no abdicar de

37 Vid. ARANGÜENA FANEGO, C., «La Orden Europea de Detención y Entrega. Análisis de las Leyes 2 y 3 de 14 de marzo de 2003, de transposición al ordenamiento jurídico español de la decisión marco sobre la euroorden», Revista de Derecho Penal, n. ${ }^{\circ}$ 10, 2003, en particular pp. 94-95.

${ }^{38}$ Léase la crítica de TOMUSCHAT, Ch., «Inconsistencias: la Sentencia del Tribunal Constitucional alemán de 18 de julio de 2005 sobre la orden europea de detención y entrega», Teoría y Realidad Constitucional, n. $^{\circ}$ 18, 2006, pp. 256 y 263; así como de VIDAL PRADO, C., «Nuevos (y viejos) recelos del Tribunal Constitucional Federal alemán frente a la eficacia del Derecho comunitario», Revista Española de Derecho Constitucional, n. ${ }^{\circ}$ 77, 2006, p. 274.

39 Auto TC 86/2011, de 9 de junio, en el marco de un recurso de amparo que trae su causa de la entrega de un ciudadano italiano acordada por la Audiencia Nacional con relación a la ejecución de una «euroorden» para el cumplimiento de una condena penal impuesta en rebeldía por un delito de quiebra fraudulenta; resuelto mediante STJUE (Gran Sala) de 26 de febrero de 2013 (asunto C-399/11, Melloni).

40 Un ejemplo paradigmático de esas tensiones lo suministra la decisión de inadmisibilidad de la desaparecida Comisión Europea de Derechos Humanos de 9 de febrero de 1990 (caso $M$ \& Co c. Alemania, demanda . $^{\circ}$ 13258/87, Serie B, vol. 64), que trae su origen de un asunto que se sustanció previamente ante el TJUE y que dio lugar a la famosa Sentencia SOLANGE II del Tribunal Constitucional Federal alemán de 8 de abril de 1986, como ha reseñado SANZ CABALLERO, S., «Interferencias entre el Derecho comunitario y el Convenio Europeo de Derechos Humanos (Luxemburgo versus Estrasburgo: ¿Quién es la última instancia de los derechos fundamentales en Europa?», Revista de Derecho Comunitario Europeo, n. ${ }^{\circ}$ 17, 2004, pp. 138-139. Por su parte, con un interesante análisis sobre los precedentes de SOLANGE II, así como de la evolución posterior y las perspectivas jurisprudenciales ante la Justicia comunitaria, PALACIO GONZÁLEZ, J., «La protección de los Derechos Fundamentales por el Tribunal de Justicia de la UE: alcance y consecuencias de la futura adhesión de la UE al Convenio Europeo», Cuadernos Europeos de Deusto, n. ${ }^{\circ}$ 40, 2009, p. 165. Con anterioridad, RODRÍGUEZ IGLESIAS, G.C., y VALLE GÁLVEZ, A., «El derecho comunitario y las relaciones entre el Tribunal de Justicia de las Comunidades Europeas, el Tribunal Europeo de Derechos Humanos y los Tribunales Constitucionales nacionales», Revista de Derecho Comunitario Europeo, n. ${ }^{\circ} 2$, 1997, p. 338: el CEDH desempeña de tal suerte «en la práctica jurisprudencial del Tribunal de Justicia, una función equivalente a la de un catálogo de derechos fundamentales formalmente reconocido»; y un repaso pormenorizado de la práctica del TJUE en esta materia en SÁNCHEZ PATRÓN, J.M., «El CEDH en la jurisprudencia del Tribunal de Justicia de las Comunidades Europeas», Revista General de Derecho, n. ${ }^{\circ}$ 680, mayo 2001, pp. 3387-3410. 
su posición para supervisar la afectación al orden constitucional germano del proceso de integración europea y sin descartar la posible adopción futura de pronunciamientos como el recién mencionado relativo a la euroorden ${ }^{41}$. Esa posición recelosa contrasta con la más europeísta del Tribunal Constitucional checo, que mediante su Sentencia de 3 de noviembre de 2009 declaró la compatibilidad sin reservas del Tratado de Lisboa en su conjunto con la Constitución de la República checa.

Recapitulando: queda dibujada una tenue frontera entre la garantía del orden constitucional del Estado que corresponde como función esencial a los Tribunales Constitucionales y la supervisión del proceso de integración europea, con respecto al cual esa garantía operada por las jurisdicciones constitucionales debería resultar, en principio, neutra ${ }^{42}$. Sobre este punto, con efecto de evitar conflictos entre el TJUE y los Tribunales Constitucionales, se ha propuesto incidir, más que en la idea de jerarquía entre órdenes de normativos, en la de un pluralismo jurídico capaz de reflejar una estructura política plural que permite soluciones conciliables y comparables ${ }^{43}$.

\section{El TJUE: ¿promotor de la primacía y desalentador del control de convencionalidad?}

De sobra conocido es que el TJUE ha sido el artífice e impulsor del principio de primacía del Derecho de la UE desde su famosa sentencia Costa/ENEL de 15 de julio de 1964 (asunto 6/64); un principio «fundamental del Derecho comunitario» e «inherente a la naturaleza específica» de la UE, habiéndose recordado que «en el momento de la primera sentencia de

${ }^{41}$ Sostiene en tal dirección en el apartado 337 de la Sentencia de 30 de junio de 2009 que «confiando en el Tribunal de Justicia de las Comunidades Europeas», para llevar a cabo el análisis de que la ejecución del Derecho de la UE en Alemania no va contra el «estándar de los derechos fundamentales en la Constitución alemana, (...) el Tribunal Constitucional Federal puede, sin embargo, reconocer el carácter final de las decisiones del Tribunal de Justicia sólo en principio» [BVerfG, 2 BvE 2/08 vom 30.6.2009, Absatz-Nr. (1 - 421)]. Con ello queda rebatido igualmente el argumento de los recurrentes sobre la supuesta pérdida de su posición de supremo garante del sistema constitucional de derechos y libertades. En el apartado 123 de la Sentencia se recoge el mencionado argumento: «La Carta de los derechos fundamentales comportará una abolición de la posición de garante que ostenta el Tribunal Constitucional Federal para la protección de los derechos fundamentales a tenor de la conocida como jurisprudencia Solange II».

42 BALAGUER CALLEJÓN, F., «Los Tribunales Constitucionales en el proceso de integración europea», Revista de Derecho Constitucional Europeo, n..$^{\circ}$ 7, 2007, p. 333.

${ }^{43}$ GIORGI, F., y TRIART, N., «National Judges, Community Judges: Invitation to a Journey Through the Looking-Glass - on the Need for Jurisdictions to Rethink the InterSystemic Relations Beyond the Hierarchical Principle», European Law Journal, Vol. 14, Issue 6, 2008, pp. 693-717. 
esta jurisprudencia constante (Costa/ENEL, 15 de julio de 1964) el Tratado no contenía mención alguna a la primacía, y todavía hoy sigue sin contenerla. El hecho de que el principio de primacía no esté incluido» en el Tratado de Lisboa no cambia «en modo alguno la existencia de este principio ni la jurisprudencia existente del Tribunal de Justicia» ${ }^{44}$.

Sin embargo, el TJUE no se ha mostrado entusiasta a la hora de promover la protección multinivel de derechos y el diálogo judicial entre jurisdicciones europeas y a escala nacional, al rechazar potenciar el control de convencionalidad como equivalente al juego del principio de primacía ${ }^{45}$. Semejante postura viene ilustrada por la STJUE (Gran Sala) de 24 de abril de 2012 (caso Servet Kamberaj, asunto C-517/10), en la que se concluye que la referencia que hace el art. 6.3 TUE al CEDH «no obliga al juez nacional, en caso de conflicto entre una norma de Derecho nacional y dicho Convenio, a aplicar directamente las disposiciones del Convenio y a no aplicar la norma de Derecho nacional incompatible con el mismo».

El asunto no era menor, pues versaba sobre la denegación de solicitud de vivienda a un residente europeo extracomunitario (albanés) de larga duración por agotamiento del presupuesto aprobado por la Provincia autónoma de Bolzano para la concesión de dicha ayuda a los nacionales de países terceros; y en la cuestión prejudicial formulada por el órgano jurisdiccional italiano se suscitó la posible sinergia entre los arts. 21 (no discriminación) y 34 (seguridad social y ayuda social) CDFUE y el principio de no discriminación reconocido por los arts. 14 CEDH y 1 del Protocolo n. ${ }^{\circ} 12$ al CEDH, sin que no obstante se trajera a colación el parámetro más específico e importante en este terreno como es el art. 31 CSE revisada (derecho a la vivienda) y la jurisprudencia del CEDS en la materia ${ }^{46}$. La postura del TJUE se distancia nuevamente de la idea de estándar mínimo y cláusula favor libertatis incluida en el art. 53 CDFUE, cuando la mayor visibilidad de la CDFUE debería jugar a favor de una paralela mayor visibilidad de esos otros instrumentos europeos en el plano interno ${ }^{47}$.

${ }^{44}$ Así se expresa la Declaración $n .^{\circ} 17$ relativa a la primacía aneja al Tratado de Lisboa, que incluye el Dictamen en tal sentido del Servicio Jurídico del Consejo sobre la primacía.

${ }^{45}$ Léase JIMENA QUESADA, L., Jurisdicción nacional y control de convencionalidad. A propósito del diálogo judicial global y la tutela multinivel de derechos, Ed. Thomson/ Aranzadi, Cizur Menor, 2013.

46 De hecho, en las Explicaciones del Praesidium anexas a la CDFUE se dice explícitamente, con respecto a su art. 34 que «el apartado 3 se inspira en el art. 13 CSE y en los arts. 30 y 31 CSEr».

${ }^{47}$ UGARTEMENDIA ECEIZABARRENA, J.I., «De la posible influencia de la Constitución europea sobre la vigente interacción constitucional europea en la tutela de los derechos fundamentales», en CARRILLO, M. y LÓPEZ BOFILL, H. (coords.), La Constitución europea, ed. Tirant lo Blanch, Valencia, 2006, p. 134. 


\section{La insuficiencia de la adhesión de la UE al CEDH}

El Tratado de Lisboa, junto a la base paralela del Protocolo n. ${ }^{\circ} 14$ al $\mathrm{CEDH}$, vino a imponer finalmente la añorada adhesión de la UE al texto convencional del Consejo de Europa para consumar así, a tenor del nuevo art. $6.2 \mathrm{TUE}^{48}$, el tránsito de la cláusula de remisión a la cláusula de adhesión al $C E D H^{49}$. Las modalidades prácticas de esa adhesión, que se encuentran en su fase final, figuran en el Proyecto revisado de Acuerdo sobre dicha adhesión formalizado en abril de 2013 en Estrasburgo entre las dos partes ${ }^{50}$.

La verdad es que el paso es necesario, sobre todo porque el propio TJUE no contribuyó precisamente a superar los obstáculos a la adhesión de la UE al CEDH mediante su Dictamen 2/1994 de 28 de marzo de 1996 ${ }^{51}$;

48 Según el art. 6.2 TUE: «La Unión se adherirá al Convenio Europeo para la Protección de los Derechos Humanos y de las Libertades Fundamentales. Esta adhesión no modificará las competencias de la Unión que se definen en los Tratados»; a renglón seguido, el apartado 3 establece: «Los derechos fundamentales que garantiza el Convenio Europeo para la Protección de los Derechos Humanos y de las Libertades Fundamentales y los que son fruto de las tradiciones constitucionales comunes a los Estados miembros formarán parte del Derecho de la Unión como principios generales». Por su lado, el Protocolo n. ${ }^{\circ} 14$, de reforma del $\mathrm{CEDH}$, dio nueva redacción al art. 59.2 del texto convencional, de manera que «la Unión Europea puede adherirse al presente Convenio».

49 Obviamente, para los derechos que están en la CEDH y no en la CDFUE seguirá jugando la cláusula de remisión (por ejmplo, el derecho al recurso en materia penal reconocido en el Protocolo n. ${ }^{\circ} 7$ al CEDH).

${ }^{50}$ Concretamente en la quinta reunión de negociación entre el Grupo ad hoc del Comité Director de Derechos Humanos del Consejo de Europa y la Comisión Europea (http:// www.coe.int/t/dghl/standardsetting/hrpolicy/Accession/Meeting_reports/47_1(2013)008rev2 _FR.pdf). Los trámites subsiguientes: pronunciamiento del TJUE sobre la compatibilidad del proyecto de acuerdo con los Tratados de la Unión; autorización por unanimidad de la firma del acuerdo por el Consejo de la UE; ratificación del acuerdo por todos los Estados miembros de la UE según las respectivas normas constitucionales; en fin, la ratificación del acuerdo por la UE y adopción de él por el Comité de Ministros del Consejo de Europa.

${ }^{51}$ Un balance crítico sobre dicho dictamen en los trabajos de FERNÁNDEZ SOLA, N., «La adhesión de la Comunidad Europea al Convenio Europeo de Salvaguardia de los Derechos Humanos. Comentario al Dictamen 2/94 del Tribunal de Justicia de las Comunidades Europeas», Noticias de la Unión Europea, n. ${ }^{\circ}$ 144, 1997, y de FLAUSS, J.F., «L'avis 2/94 de la CJCE du 28 mars 1996», Bulletin des droits de l'homme, n. ${ }^{\circ}$ 6, 1996. Al respecto, y tras un análisis de la praxis jurisprudencial, ha observado ASTOLA MADARIAGA, J., «La importancia de la paulatina codificación de los principios generales del derecho comunitario», en CORCUERA ATIENZA, J. (coord.), La protección de los derechos fundamentales en la Unión Europea, ed. Dykinson/Instituto internacional de sociología jurídica de Oñati, Madrid, 2002, p. 191: «hasta el momento, han existido divergencias en las interpretaciones del contenido de los derechos entre los Tribunales de Estrasburgo y de Luxemburgo, aunque siempre se ha dado el caso de que la jurisprudencia de Luxemburgo precediese a la de Estrasburgo, por lo que nunca se ha producido un incumplimiento, propiamente dicho, de la CEDH por parte del derecho comunitario». Claro que, hasta tanto se opere la adhesión de la UE al 
pero se trata de un paso insuficiente en términos de indivisibilidad de todos los derechos fundamentales. La CDFUE ha contribuido a fomentar la implacable vis atractiva del CEDH y del TEDH a diferencia del agraviado o relegado estatuto de la CSE o de la ausencia notoria de toda referencia a la jurisprudencia del CEDS.

El Parlamento Europeo ha sido consciente de esa insuficiencia, y no por casualidad en su Resolución de 19 de mayo de 2010 sobre los aspectos institucionales de la adhesión de la UE expresó que ese paso esencial debía completarse con la adhesión a la CSE revisada de 1996 «en coherencia con los acervos ya consagrados en la CDFUE y en la legislación social de la UE» (apartados 30-32). El reto de esa indivisibilidad y coherencia armonizadora no deriva de un mero prurito académico sino, como asimismo expresa el Parlamento Europeo en la citada Resolución, «para el beneficio de los ciudadanos, de la democracia y de los derechos humanos en Europa y en la UE, y para garantizar el respeto y la salvaguardia de los derechos humanos».

A fin de cuentas, ninguna obsesión es recomendable, y la «obsesión convencional» (por el CEDH y por el TEDH, a pesar de su innegable condición de «buque insignia» del Consejo de Europa) no puede esconder que el CEDH y el TEDH no fueron creados como instrumento y jurisdicción europeos de derechos sociales, no pudiendo atender las «obsesivas expectativas» de la academia: pese a la interesante jurisprudencia social del TEDH, tal vez le pedimos demasiado y, entonces, nos sentimos decepcionados cuando se muestra circunspecto o timorato en relación con situaciones de vulnerabilidad derivadas de pobreza o exclusión social ${ }^{52}$ o de discapacidad ${ }^{53}$.

En fin, ante tal postura, permítaseme incidir en ejemplos prácticos de efectividad de las decisiones del CEDS que erigen a la CSE del Consejo de Europa como instrumento jurídico europeo por excelencia de los derechos sociales ${ }^{54}$, con ejecución (efectividad) de decisiones en pocos meses

CEDH, sigue existiendo el posible dilema para los Estados de respetar el Derecho de la UE incumpliendo para ello el CEDH o viceversa y, aunque se hable de responsabilidad de los Estados, en realidad se está poniendo en cuestión la responsabilidad de la UE pese a no ser Parte Contratante del CEDH (BENOÎT-ROHMER, F., «L'adhésion de l'UE à la CEDH», Revue Universelle des Droits de l'Homme, n. ${ }^{\circ} 1-2$, vol. 12, 2000, p. 58).

52 Decisión de inadmisibilidad del TEDH Budina c. Rusia, de 18 de junio de 2009 (sobre precariedad de una persona mayor a causa de la insuficiente pensión de jubilación).

${ }^{53}$ Entre otras, SSTEDH Botta c. Italia, de 24 de febrero de 1998, y Molka c. Polonia, de 14 de abril de 2006, o Decisión de inadmisibilidad Jitka Zehnalova y Otto Zehnal c. República Checa, de 14 mayo de 2002.

${ }^{54} \mathrm{Me}$ remito a las siguientes ilustraciones de efectividad de las decisiones del CEDS propiciadas, en pocos meses, por los distintos niveles nacionales del poder público (judicial, ejecutivo y legislativo): 1) Un ejemplo de cómo a la modificación normativa puede anticiparse una ejecución vía judicial, a través del ejercicio del control de convencionalidad por las juris- 
frente a sentencias del TEDH que han necesitado una década para su efectivo cumplimiento ${ }^{55}$.

\section{La consideración de la CDFUE como verdadero texto fundacional ante las medidas anti-crisis}

Llegados a este punto, es obvio que el alcance de la consagración de la CDFUE como parte integrante de los Tratados fundacionales evoca mucho más que una discusión académica, que carece de toda virtualidad si no se acomete la vigencia de aquélla como instrumento efectivo de protección de las personas, sobre todo en el panorama de crisis que nos acucia. La reflexión puede formularse en términos simples, pero de gran calado: ¿Acaso las medidas anti-crisis y de austeridad propuestas e impuestas por la Troika (Fondo Monetario Internacional, Comisión Europea y Banco Central Europeo), con los sacrificios y recortes sociales conocidos, han sido coherentes y respetuosas con la propia CDFUE? La cuestión no es baladí, tanto en términos sustanciales como procedimentales, pues la controvertida naturaleza de los actos normativos de la Troika difícilmente se acomodan a los contenidos materiales de la CDFUE (derechos sociales) y a la posición jerárquico-normativa superior de la misma CDFUE como parte integrante del Derecho primario.

dicciones internas, puede verse en la Reclamación n. ${ }^{\circ}$ 14/2003 (caso Federación internacional de ligas de derechos humanos c. Francia, decisión de fondo de 7 de septiembre de 2004) llevada a la práctica por el máximo escalón de la jurisdicción administrativa francesa (el Consejo de Estado, mediante su Decisión de 7 de junio de 2006, Association Aides et autres) en materia de asistencia médica a menores extranjeros en situación irregular. 2) Una modalidad de ejecución por vía ejecutiva la ofrece la retirada de un libro de texto del sistema educativo que incluía manifestaciones homófobas contrarias a la educación sexual y reproductiva no discriminatoria impuesta por el art. 11 CSE (Reclamación n. ${ }^{\circ}$ 45/2007, Interights c. Croacia, decisión de fondo de 30 de marzo de 2009). 3) Y una ilustración sobre cumplimiento por vía legislativa, y dentro de un razonable plazo, la Reclamación n. . 48/2008 (ERRC c. Bulgaria, Decisión de fondo de 18 de febrero de 2009), tras la cual el Parlamento nacional procedió a modificar la Ley de Asistencia Social para suprimir la limitación temporal en el disfrute de las prestaciones de subsidio de desempleo y conformarse así al derecho a la asistencia social, entendida como recursos mínimos garantizados, reconocido en el art. 13 CSE.

55 Por ejemplo, la STEDH de 13 de junio de 1979, caso Marckx c Bélgica [el Gobierno belga tardó once años en modificar la legislación civil que discriminaba a los hijos extramatrimoniales en cuanto a derechos sucesorios (véase a este respecto la STEDH de 29 de noviembre de 1991, caso Vermeire c. Bélgica)]; diversamente, en el curso de la sustanciación de las Reclamaciones n. ${ }^{\circ}$ 33/2006 (Movimiento Internacional ATD-Cuarto Mundo c. Francia) y 39/2006 (FEANTSA c. Francia), el propio CEDS tomó nota en sendas Decisiones de fondo de 5 de diciembre de 2007 ( $\$ 54$ y $\$ 53$, respectivamente) de la nueva Ley francesa n. ${ }^{\circ}$ 2007-290 de 5 de marzo de 2007 sobre el derecho a la vivienda (Loi n. ${ }^{\circ} 2007-290$ du 5 mars 2007 instituant le droit opposable au logement). 
Es cierto que ha mediado una aplastante atención a las medidas regresivas frente a la satisfacción de las necesidades sociales, motivada por el mayor eco - incluso mediático- de sesgados análisis económicos del Derecho y por la propia asimetría «a la baja» con la que, como se ha analizado más arriba, formalmente se han consagrado los derechos sociales en la CDFUE. Ahora bien, ese poco ponderado enfoque no debería descuidar que el alcance de esos derechos sociales tiene que ser inexorablemente aprehendido a la luz de los otros instrumentos europeos que han servido de base a la elaboración del catálogo de derechos sociales de la CDFUE y que integran el juego sustancial «al alza» del nivel de protección de ésta (art. 53).

Desde esta perspectiva, las actuaciones de la Troika (con las discrepancias internas entre las tres instituciones integrantes que han trascendido en medios de comunicación) no han superado el nivel de la CSE ni el examen del CEDS: éste así lo ha puesto de manifiesto mediante Decisiones de fondo de 23 de mayo de 2012 de resolución de las Reclamaciones colectivas n. ${ }^{\circ} 65 / 2011$ y n. ${ }^{\circ} 66 / 2011$ (ambas contra Grecia, formuladas por los sindicatos griegos Federación general de empleados de las compañías públicas de electricidad y Confederación de sindicatos de funcionarios públicos). En la primera decisión (Reclamación n. ${ }^{\circ}$ 65/2011), el Comité concluyó que se había producido una violación del art. 4.4 CSE, por cuanto la ley nacional que autorizaba el despido sin preaviso ni indemnización a los asalariados con contrato de duración indefinida durante un período inicial de doce meses es incompatible con dicha disposición de la Carta ${ }^{56}$; en la segunda decisión (Reclamación n. ${ }^{\circ}$ 66/2011), el Comité llegó a la conclusión de violación de diversas disposiciones de la CSE (arts. 4.4, 7.7, 10.2 y 12.3), al enjuiciar las disposiciones restrictivas sobre vacaciones anuales, sistemas de aprendizaje y formación, y cobertura de la seguridad social en los llamados «contratos de aprendizaje especiales» para asalariados de entre 15 a 18 años, así como las disposiciones referentes a la irrisoria remuneración (un pequeño porcentaje del salario mínimo nacional) susceptible de ser percibida por los asalariados recién incorporados al mercado laboral menores de 25 años.

El caso es que ambas decisiones han tenido bastante eco mediático, por cuanto el Gobierno griego aducía que las medidas declaradas contrarias a la CSE por el CEDS habrían sido en cambio adoptadas por «imposición» de

56 En la doctrina española ya se ha criticado que esas decisiones del Comité frente a Grecia resultarían aplicables a España (de necesaria consideración por los órganos jurisdiccionales internos a tenor de los mandatos interpretativo del art. 10.2 y aplicativo del art. 96 de la Constitución española), por ejemplo con relación al análogo período de prueba de un año fijado para el contrato de apoyo a emprendedores: SALCEDO BELTRÁN, C., «El contrato de apoyo a emprendedores: su difícil encaje en la normativa internacional, europea y nacional», Revista de Derecho Social, n. ${ }^{\circ}$ 62, 2013, pp. 93-122. 
la Troika; lo cual, lógicamente, ha suscitado otra vez las posibles divergencias de enfoques entre el Consejo de Europa y la $\mathrm{UE}^{57}$, pero debería llevar a una reflexión más profunda sobre la propia coherencia de acción en el seno de la UE (en este caso, entre las medidas de la Troika y el parámetro prevalente de la CDFUE).

\section{Conclusión: superando pequeños pasos y tropiezos en el camino de la consagración jurídica de los derechos fundamentales}

La importante posición jurídica de la CDFUE alcanzada mediante el Tratado de Lisboa, al máximo nivel jerárquico-normativo como parte integrante de los Textos fundacionales, no debiera llevar a la autocomplacencia, a tenor del estatuto asimétrico de los derechos fundamentales (en detrimento de los sociales) que se ha plasmado formalmente en ella.

Las diversas asimetrías son tributarias de los pequeños pasos conseguidos y tropiezos sufridos en el camino de esa consagración jurídica, que se ha visto marcado por el empleo (justificado, pero excesivo) de unas energías y unos recursos económicos y materiales inusitados en la elaboración de la propia CDFUE (sin conciencia de su real utilidad) o en la obsesión por la adhesión de la UE al CEDH (necesaria, pero insuficiente, al relegar - como también ha resaltado el Parlamento Europeo, supra - la paralela adhesión a la CSE en virtud de «los valores indivisibles y universales de la dignidad humana» proclamados en el Preámbulo de la CDFUE).

El confuso estatuto de la CDFUE, por las reseñadas asimetrías normativas recogidas en ella, lleva a cuestionarse con fundamento sobre si la nueva base normativa «fundacional» no habría comportado paradójicamente un debilitamiento del reconocimiento formal con respecto a la jurisprudencia pretoriana del TJUE sobre derechos fundamentales anterior a la CDFUE. Pareciere como si la CDFUE, teóricamente concebida para dotar de mayor presencia o visibilidad, hubiera comportado una suerte de neutralización de la importante proyección de los principios generales sobre derechos fundamentales en la jurisprudencia precedente del TJUE.

En dicho contexto, no se trata de reivindicar ese papel pretoriano, ya jugado con anterioridad a la vigencia de la CDFUE, bajo la forma de acti-

57 Como ejemplo, véase el artículo titulado «L'austérité grecque jugée illégale» en el diario francés Le Figaro, del 19 de octubre de 2012 (Le Figaro.fr / France), en donde puede leerse: «Europa critica a Europa. El Comité Europeo de Derechos Sociales, un órgano del Consejo de Europa, ha juzgado ilegales diversas medidas adoptadas por Grecia para flexibilizar su mercado laboral en respuesta a las demandas de reforma formuladas por la UE y el FMI». 
vismo judicial; pero sí, al menos, compatibilizar la tenue construcción normativa (a través de la CDFUE) con la nada desdeñable construcción judicial (sin menoscabo del acervo jurisprudencial del TJUE) de la Europa de los derechos fundamentales. Pareciere también como si el redactor de la CDFUE hubiera estado más concernido por el juego de la distribución de competencias entre la UE y los Estados miembros (y el celo de éstos por preservar su identidad constitucional, lo cual evoca una especie de efecto «Brighton» - plasmado en el Protocolo n. ${ }^{\circ} 15$ al CEDH - atiente a la preocupación por el margen de apreciación nacional ante el TEDH) que por el despliegue de efectos prácticos de los niveles de protección presentes en la propia CDFUE.

Bajo tal prisma, el TJUE debería mostrar una mayor voluntad jurisdiccional positiva no sólo para seguir velando por la primacía del Derecho de la UE, sino asimismo para favorecer la armonización normativa y el diálogo judicial en el ámbito de la tutela multinivel de derechos, abriéndose a la recepción de interpretaciones «ajenas» cuando sean más favorables para la vigencia de los derechos humanos (favor libertatis o pro personae); a ello apunta no únicamente la CDFUE (art. 53), sino asimismo las cláusulas equivalentes en los dos tratados más emblemáticos del Consejo de Europa (art. 53 CEDH y art. H de la CSE revisada).

Y una última reflexión conclusiva en clave de actualidad: la CDFUE no sólo no se está perfilando desgraciadamente como un antídoto frente a la crisis, sino que la crisis de la Europa de los mercaderes ha puesto en riesgo un acervo jurídico susceptible de manifestarse en una crisis de la Europa de los derechos humanos al verse debilitado su texto fundacional sustancial (la CDFUE) a causa de las medidas regresivas impulsadas por la Troika. Como consecuencia de la filosofía imperante en la construcción europea desde los Tratados fundacionales, si la economía va mal, el resto de la UE va mal, o peor; como evocó Jean Monnet en su última etapa, sobre no haberse introducido la cultura (también la de los derechos humanos) como objetivo prioritario, al fallar la prioridad básica que se promovió (la económica), se pone en riesgo el funcionamiento conjunto del edificio europeo. 